Potential disadvantages of the technique could be wound-healing disturbances, which were not observed in this particular case.

Although the use of this new technique should remain limited to selected cases, it represents a valuable alternative to the already existing spectrum of thoracic incisions.

\section{References}

1. Shields TM, LoCicero J, Ponn RB. General thoracic surgery. 5th ed. Philadelphia: Lippincott Williams \& Wilkins; 2000.
2. Becker RM, Munro DD. Transaxillary minithoracotomy: the optimal approach for certain pulmonary and mediastinal lesions. Ann Thorac Surg. 1976;22:254-9.

3. Cooper JD, Al-Jilaihawa AN, Pearson FG, Humphrey JG, Humphrey HE. An improved technique to facilitate transcervical thymectomy for myasthenia gravis. Ann Thorac Surg. 1988;45(3):242-7.

4. Kaiser LR, Pasque MK, Trulock EP, Low DE, Dresler CM, Cooper JD. Bilateral sequential lung transplantation: the procedure of choice for double-lung replacement. Ann Thorac Surg. 1991;52(3):438-46.

5. Korst RJ, Burt ME. Cervicothoracic tumors: results of resection by the "hemi-clamshell" approach. $J$ Thorac Cardiovasc Surg. 1998;115(2):286-94

\title{
Repair of acute postinfarction ventricular septal defect by endocardial patch exclusion through the aortic valve orifice
}

\author{
Angelo A. Vlessis, MD, PhD, and Timothy Hanlon, MD, Bend, Ore
}

T

he repair of acute postinfarction ventricular septal defects (VSDs) remains a contemporary challenge for cardiac surgeons. The treatment of this devastating condition has evolved considerably during the past 2 decades. Initial experiences with immediate operative intervention in the 1970s were dreadful, and there was therefore little enthusiasm for acute surgical intervention. In the early 1980s, delayed repair was an accepted practice. ${ }^{1}$ Patients were stabilized with an intraaortic balloon pump for 3 weeks before an attempt at surgical intervention. Those patients who survived the waiting period understandably had better surgical outcomes. Regrettably, patients frequently died or became more unstable during the waiting period. This prompted some surgeons to reconsider earlier repair. ${ }^{2}$ Patch replacement of the ventricular septum evolved as the preferred method of repair. Mortality remained high, however, and studies from the late 1980s and early 1990s reported mortality rates of $40 \%$ to $70 \%{ }^{3,4}$ In 1995 David and colleagues ${ }^{5}$ introduced the idea of left ventricular endocardial patch exclusion of the infarcted ventricular septum. The operative mortality reported with this new approach was an inspiring 14\%. Many surgical groups, including our own, have adopted the technique with equivalent success. Our case report describes the technique of endocardial patch exclusion of an acute postinfarction VSD through the aortic valve orifice, thereby avoiding ventriculotomy and the subsequent

From the Heart Institute of the Cascades, Bend, Ore.

Received for publication March 17, 2004; accepted for publication April 20, 2004.

Address for reprints: Angelo A. Vlessis, MD, PhD, Cardiothoracic Surgeons, PC, 2705 NE Conners Ave, Suite A, Bend, OR 97701 (E-mail: vlessis@bendcable.com).

J Thorac Cardiovasc Surg 2005;129:223-4

$0022-5223 / \$ 30.00$

Copyright $\odot 2005$ by The American Association for Thoracic Surgery doi:10.1016/j.jtcvs.2004.04.038

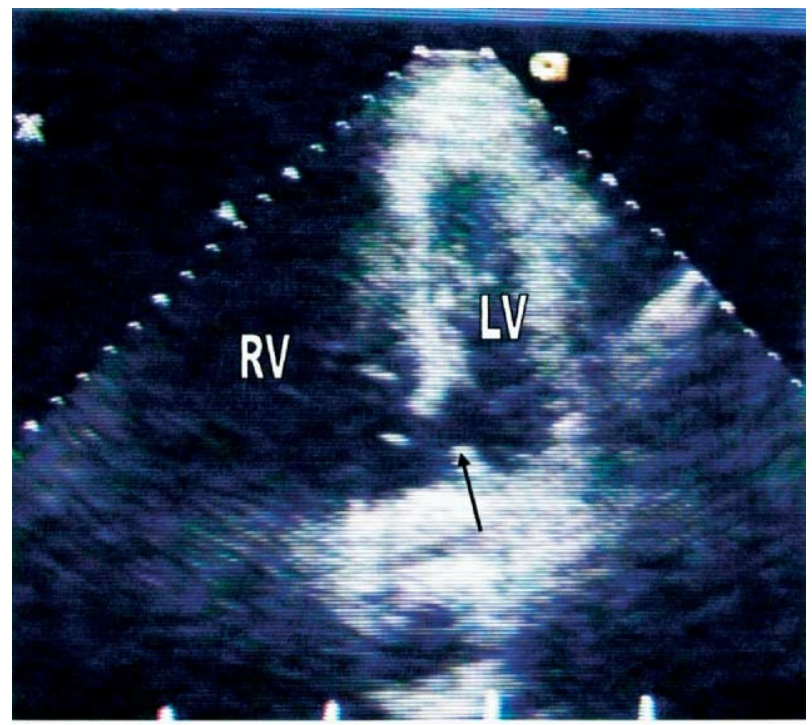

Figure 1. Preoperative echocardiogram demonstrating large acute VSD (black arrow). RV, Right ventricle; $L V$, left ventricle.

right ventricular dysfunction that often leads to death or prolongation of in-hospital recovery.

\section{Clinical Summary}

A 66-year-old man came to his primary care physician with a report of 8 to 10 days of epigastric discomfort followed by acute onset of shortness of breath and orthopnea. A heart murmur was detected, and the patient was referred urgently for cardiologic evaluation. A chest radiograph showed congestive heart failure with bilateral pleural effusions. Laboratory studies revealed renal insufficiency. A transthoracic echocardiogram showed a $2.1 \mathrm{~cm}$ VSD in the inferobasilar septum, right ventricular dysfunction, pulmonary hypertension, and an akinetic inferior myocardium 


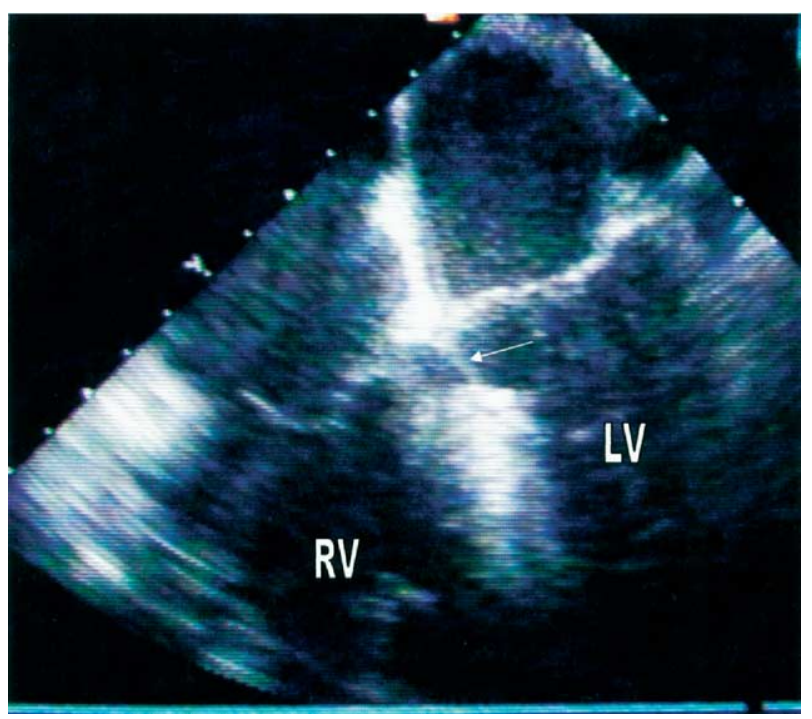

Figure 2. Postoperative echocardiogram demonstrating repaired acute VSD. White arrow points to thin pericardial patch that excludes defect from right ventricle $(R V)$. $L V$, Left ventricle.

(Figure 1). Coronary angiography demonstrated an occluded dominant right coronary artery. Left ventriculography confirmed the presence of a large VSD and a large left-to-right shunt. An intraaortic balloon pump was placed, and the patient underwent urgent operation.

A standard median sternotomy was performed, and standard cannulation and cardioplegia techniques were used. The ascending aorta was then opened through a low transverse aortotomy. The aorta provided an approximately $25-\mathrm{mm}$ opening into the left ventricular cavity. An aortic leaflet retractor was placed to retract the right coronary leaflet, and the VSD was visualized in the posterior basal septum.

The defect was surrounded by yellow, necrotic ventricular muscle. The anterior third of the septum was viable, as was the posterior apical septum. A $4 \times 3$-cm oval glutaraldehyde-fixed bovine pericardial patch was prepared. Beginning distally in the septum, the pericardial patch was sewn to the viable left ventricular endocardium with running 4-0 polypropylene suture. The superior suture was run along the viable anterior portion of the ventricular septum to the area of the central fibrous body, staying at least $1 \mathrm{~cm}$ away from the necrotic perimeter of the defect. The inferior sutures were placed along the inferior and posterior left ventricular free wall, coursing up to the right trigone of the mitral annulus and then joining the anterior suture at the central fibrous body. The most difficult suture placement was along the inferior septum and inferior free wall of the ventricle. A nerve hook was used to retract the anterior mitral valve leaflet laterally, thereby facilitating suture placement into the viable portion of the inferior ventricle wall muscle. The patch and sutures coursed around the posteromedial papillary muscle head without inducing distortion of those mitral leaflet attachments. After completion of the suture line, the endocardial patch fit nicely within the left ventricle, was secured to viable tissue around the area of infarct, and generously covered the defect into the right ventricle. The aortotomy was closed with a running suture, and the aortic crossclamp was removed during venting of the ascending aorta. The patient was warmed to normothermia and weaned from bypass support with a low-dose dopamine infusion only. Atrioventricular pacing was required. The pulmonary artery pressures were greatly reduced from preoperative values.

A transesophageal echocardiogram was performed immediately after weaning from bypass pump support. There was no evidence of residual VSD. The endocardial patch was visible as a thin membrane in the area of the defect (Figure 2).

The patient was weaned from ventilatory support 5 hours after the operation. He remained in heart block, and a biventricular pacemaker was placed on postoperative day 4 . He was discharged home the next day ambulating well without supplemental oxygen and taking a regular diet.

\section{Discussion}

The treatment of acute VSD continues to present a formidable challenge to cardiac surgeons today. Surgical treatment has evolved as experience with various treatment strategies are gained, shared, and discussed among surgeons. Advancements in surgical technique and intensive care unit management have reduced the overall mortality. Our case report illustrates another potential approach for treatment of the patient with acute VSD. The main advantage of this approach is avoidance of ventriculotomy. Access to the left ventricular endocardium is gained through the aortic valve orifice. The technique is best suited for basilar and inferior infarcts, in which case retraction of the infarcted heart anteriorly is necessary to perform the ventriculotomy through the infarcted inferior wall. Defects in the anterior and apical septum are probably still best approached through the infarcted anterior wall, because visualization and suture placement would be more difficult through the aortic valve orifice.

The main limitation of this approach is the small orifice through which the surgeon works to gain access to the left ventricular cavity. The hole is deep and narrow. The entire area of interest cannot be visualized simultaneously during the repair. With patience and careful placement of each stitch, however, this approach does provide a feasible alternative to the standard inferior ventriculotomy.

\section{References}

1. Baillot R, Pelletier C, Trivino-Marin J, Castonguay Y. Postinfarction ventricular septal defect: delayed closure with prolonged mechanical circulatory support. Ann Thorac Surg. 1983;35:138-224.

2. Thomas CS, Alford WC, Burrus GR, Glassford DM, Stoney WS. Urgent operation for acquired ventricular septal defect. Ann Surg. 1982;195:706-11

3. Blanche C, Khan SS, Matloff JM, Chaux A, DeRobertis MA, Czer LS, et al. Results of early repair of ventricular septal defect after an acute myocardial infarction. J Thorac Cardiovasc Surg. 1992;104:961-5.

4. von Segesser LK, Siebenmann R, Schneider K, Jenni R, Gallino A, Turina M. Postinfarction ventricular septal defect-surgical strategies and results. Thorac Cardiovasc Surg. 1989;37:72-5.

5. David TE. Operative management of postinfarction ventricular septal defect. Semin Thorac Cardiovasc Surg. 1995;7:208-13. 